\title{
Role of Transvaginal Ultrasonography in the evaluation of Uterine Fibroids: a regional observation in Bangladesh.
}

\author{
Mukthadira ${ }^{1}$, Hira $\mathrm{MT}^{2}$, Sharma $\mathrm{NK}^{3}{ }^{3}$ Rahman $\mathrm{ASMM}^{4}$, Razzaque $\mathrm{MA}^{5}$
}

Hossain $M Z^{6}$, Farzana $\mathrm{MN}^{\dagger}$, Naznin $\mathrm{R}^{8}$, Hossain $\mathrm{M}^{9}$

\begin{abstract}
Uterine fibroids, also known as leiomyomas, are the most common uterine neoplasms. Although benig, they can be associated with a significant number of morbidity and are the most common indication for hysterectomy. Transvaginal ultrasonography (TVS) has become essential in the diagnosis and management of the uterine fibroids. TVS provides a detailed examination of uterus and ovaries. However, there is no nation-wide and regional clinical study on the use of TVS for the evaluation of uterine fibroids in Bangladesh. In this work, a cross-sectional study toob serve the role of TVS in the evaluation of uterine fibroids in a region of Bangladesh (Greater Mymensingh). In the diagnosis of uterine fibroids by TVS, we observed that $35(81.4 \%$ ) cases (out of 43 ) are fibroids and $8(18.6 \%)$ cases are non-fibroids. In histopathological diagnosis, we found 36 (83.7\%) cases are uterine fibroids, and 7 (16.3\%) cases are without fibroids. In this study, TVS diagnosed uterine fibroids with a sensitivity of $94.4 \%$, the specificity of $85.71 \%$, the accuracy of $97.6 \%$, the positive predictive value of $97.1 \%$ and negative predictive value of $75 \%$. The results demonstrate that TVS has the potential to become a useful imaging tool for the evaluation of uterine fibroids.
\end{abstract}

CBMJ 2018 July: vol. 07 no. 02 P: 17-23

Key words: Transvaginal ultrasonography, Uterine fibroids.

\section{Introduction}

Uterine fibroids also are known as leiomyomas or myomas, are the most prevalent uterine neoplasms. They are benign tumours of smooth muscle origin with varying amount of fibrous connective tissue Wilde and Scott-Barrett (2009). Atleast $20 \%$ of all women and $40 \%$ of women over the age of 40 years have uterine lieomyomas Ibrar $F$ (2010). Fibroids can be found inside an intramural myometrial wall, bulging into the endometrial cavity (submucosal), positioned almost entirely inside the endometrial cavity (intracavitary) or on the uterine surface Aflatoonian (2011); Podar (2008). Subserosal leiomyomas may be beneath the uterine surface as exophytic or pedunculated Yeh (1999). The leiomyomas are hormone-dependent neoplasia to both estrogen and progesterone Rein et al. (1995). Estrogen and progesterone receptors are in higher concentrations in leiomyomas than in the normal surrounding myometrium. The growth rate of leiomyomas is related to their numberof estrogen and progesterone receptor
1. Dr. Mukthadira, Assistant Professor (C.C), Department of Radiology \& Imaging, Community Based Medical College Bangladesh.

2. MutaTah Hira, School of Health and Life Sciences, Teesside University, UK.

3. Dr. Netay Kumer Sharma, Assistant Professor, Department of Radiology \& Imaging, Community Based Medical College Bangladesh.

4. Dr. A S M Mahbubur Rahman, Superintendent, Netrokona Adhunik Sadar Hospital, Bangladesh.

5. Dr. M.A Razzaque, School of Computing, Eng. \& Digital Tech., Teesside University, UK.

6. Dr. Md Zakir Hossain, Assistant Professor, Department of Radiology \& Imaging Mymensingh Medical College Bangladesh.

7. Dr. M N Farzana, Medical Officer, Department of Radiology \& Imaging, Community Based Medical College Hospital Bangladesh.

8. Dr. Rubiat Naznin, Assistant Professor, Department of Physiology Community Based Medical College Bangladesh.

9. Dr. Maria Hossain, Assistant Professor (C.C), Department of Physiology, Community Based Medical College Bangladesh.

Address of correspondence:

Mobile: 01712513143

Email:

muktadira51@gmail.com 
Walker and Stewart (2005); Murase et al. (1999). They often increase in size during pregnancy and usually after menopause. Early age at menarche and obesity are risk factors for the development of fibroids as they increase exposure to estrogen Jr.(1995). The majority of women with fibroids are asymptomatic. However, $20 \%-50 \%$ of them had symptoms such as menorrhagia, pelvic pain, and infertility or complication during pregnancy Chaparala et al. (2004); Wallach and Vlahos (2004). A large fibroid can present as an abdominal mass or with symptoms secondary to mass effects such as constipation and urinary frequency or retention Sudderuddin et al. (2014).

The presence of symptomatic fibroids is the most common hysterectomy indication, accounting for roughly one-third of those performed. Surgery is traditionally the treatment for fibroids. However, treatment with uterine artery embolization (UAE) has been performed more and more in recent years and has been effective in traditional surgery. UAE is an option when uterine preservation is desired or when a patient is unable to an open surgical procedure. Often treatment options include myomectomy or administration of gonadotropin-releasing hormone $(\mathrm{GnRH})$ an alogue.

Sonography is the most cost-effective procedure for confirming the myomas diagnosis. Sonography, however, maynot detect small lesions and may be inaccurate in identifying exophytic subserosal myomas and distinguishing myomas from leiomyosarcomas Sudderuddin et al. (2014). Transvaginal sonography is the technique with the most readiness and cost-effectiveness. This can also help in the differentiation of myomas from other pelvic conditions. Transvaginal sonography scans for the diagnosis of small fibroids more sensitive, but when the uterus is bulky or retroverted uterine fundus may lie outside the field of view Parker (2007).

TVS has a high sensitivity for detecting myomas in a uterus of fewer than ten weeks size.
The use of high-frequency probes improves the sensitivity for diagnosing small myomas. However, their precise location respect to the uterine cavity of ten remains uncertain Prayson RA (1995).

Sonographic appearance of myomas can be variable, but frequently they appear as welldefined symmetrical hyperechoic and heterogeneous masses. However, areas of calcification or hemorrhagic may appear anechoic. Sonography may be inadequate for determining the precise number and position of myomas. However, TVS is reliable for less than $375 \mathrm{ml}$ within a total volume or containing four or fewer myomas Ferreira (1971). Leiomyomas are benign tumours predominantly composed of smooth muscle cells separated by variable amounts of fibrous connective tissue Garg et al. (2011); Ferdows et al. (2017); Bhatiyani et al. (2018); Wo'zniak and Wo'zniak (2017).

It is clear from the above discussion is that TVS has the potential to detect leiomyomas or uterine fibroids, and generally, sonography machines are available in most places of Bangladesh. However, TVS is not an established method for detecting uterine fibroids in Bangladesh Ferdows et al. (2017) and few studies, specific to a region or districts are available. For example, in a recent study Ferdows et al. (2017), authors have used Ultrasound for in fertility study in a region of Dhaka city. In this study, aim to demonstrate TVS as asensitive and effective modality in the diagnosis and mapping of uterine fibroids. This study provides reliable and relevant information for the diagnosis, and accurate uterine fibroid count, location, and measurement. The study results also have the potential to motivate and assist doctors and patients in improving treatment planning, such as embolization of the uterine artery as minimally invasive surgery.

\section{Materials and Methods}

This cross-sectional study was carried out in the Department of Radiology and Imaging, Mymensingh Medical College Hospital, Mymensingh, from July 2012 to June 2014. 
The research protocol was approved by the thesis committee (Local ethical committee). The objectives of the study, along with its procedure, alternative diagnostic methods, risks and benefits of this study were explained to the patients in an easily understandable local language. Then informed consent was taken from every patient. We assured that all information and records would be kept confidential and the procedure would be helpful for both the physician and the patients in making rational approach of patient management. In this study considered a total of 43 women ages 21 to 50 years in the study. They were referred by the outpatient department (OPD) and inpatient department of the hospital to the Department of Radiology and Imaging for transvaginal ultrasonography to detect uterine fibroids. Patients were selected by followings:

\section{Inclusion criteria:}

Patient having clinical manifestation of uterine fibroids.

\section{Exclusion criteria:}

- Patient who refused TVS examination,

- Histopathology report was unavailable,

- Have a huge fibroid and

- Patients who refused to do surgery.

\section{a. Method of Transvaginal Ultrasonography}

In this study Medison Sonoace X8 with a $7 \mathrm{MHz}$ transvaginal transducer used in the transvaginal sonography. The urinary bladder needs to be empty to bring the pelvic organs into the focal zone of the transvaginal transducer. A female staff member was present in the lab room during the entire examination to act as achaperone.

The transducer is prepared with ultrasound coupling gel and then covered with a protective sheath, usually a condom. Air bubbles were eliminated to avoid artifacts and then applied an external lubricant to the outside of the protective covering. Finally, the transducer was inserted into the vagina with the patient's supine. Knees gently flexed and hips elevated slightly on a pillow. The elevated hips allow free movement of the transducer by the operator. With gentle rotation and angulations of the transducer, both sagittal and coronal images can be obtained. Following the examination, the transducer is removed from the vagina with the sheath intact. The sheath is discarded and the transducer is cleaned of gel. The transducer is then immersed in a disinfectant, according to the manufacturers preferred method.

\section{Results}

In this study produced two different set of results from the study: (i) for the studied sample (43 patients) Figure 1 and Table 1, and (ii) for the studied fibroid sample (35 patients)- Tables 2, 3 and 4.

Analysed the age distribution of the study patients. Majority of the patients were found in the age group 4th decade, which was 19 $(44.2 \%)$ and the mean age was 37.7 with standard deviation 7.3 years with a range from 21 to 50 year. We observed the patients common symptom and found that excessive per vaginal during menstruation in 36 (83.7\%) patients, 26 patients had lower abdominal pain $(60.5 \%), 17(39.5 \%)$ patients had a lump in the lower abdomen, 15 (34.8\%) patients had dysmenorrhoea. Postmenopausal bleeding and subfertility were seen in $7(16.2 \%)$ patients.

Table 1 and Figure 1 present the result of TVS diagnosis. As shown in the figure and table, 35 $(81.4 \%)$ of the patients detected with fibroids and $8(18.6 \%)$ detected with Non-Fibroid (NF). Specifically, out of the 8 NF patients, $4(9.3 \%)$ were detected with adenomyosis, 2(4.6\%) with a bulky uterus and $2(4.6 \%)$ with an endometrial polyp. On the other hand, out of the 35 fibroids patients, $23(65.7 \%)$ cases appeared as hypoechoic, $10(28.6 \%)$ cases as a mixed echoic pattern and $2(5.7 \%)$ cases as calcification. We also found that 25 cases $(71.4 .7 \%)$ of the fibroids cases were intramural fibroids, $08(22.9 \%)$ cases were Submucosal fibroids, and 2 (5.7\%) were subserosal fibroids. The posterior wall of the uterus was involved in 16 cases $(45.7 \%)$ \& anterior wall was involved in $10(28.6 \%)$ cases of the fibroids. Both walls are involved in $07(20 \%)$ cases, and the 
fundus is involved in 2 (5.7\%). Finally, we observed the size and number of fibroids in the patients, and these are discussed in the discussion section.

Table 1: Distribution of the patient $(n=43)$ by TVS Diagnosis

\begin{tabular}{|l|c|c|}
\hline USG findings & Number & Percentage (\%) \\
\hline Fibroid & 35 & $81.4 \%$ \\
\hline Adenomyosis (NF) & 04 & $9.3 \%$ \\
\hline Bulky uterus (NF) & 02 & $4.65 \%$ \\
\hline Endometrial polyp (NF) & 02 & $4.65 \%$ \\
\hline Total & 43 & $100 \%$ \\
\hline
\end{tabular}

Table 2: Distribution of the fibroid patients ( $\mathrm{n}$ = 35) based on appearance

\begin{tabular}{|l|c|c|}
\hline Appearance of fibroids & Number & Percentage (\%) \\
\hline Hypoechogenic mass & 23 & $65.7 \%$ \\
\hline Mixed echogenic mass & 10 & $28.6 \%$ \\
\hline Calcification & 2 & $5.7 \%$ \\
\hline Total & 35 & $100 \%$ \\
\hline
\end{tabular}

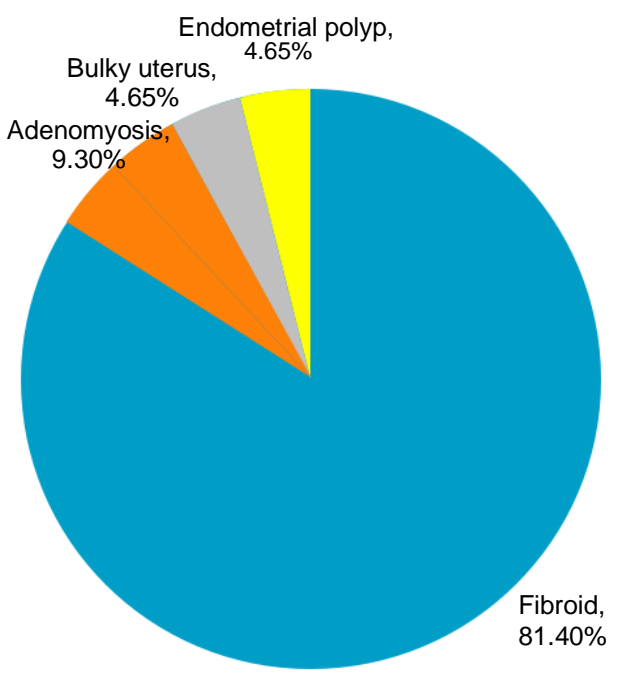

Figure 1: Distribution of patients according to TVS diagnosis $(n=43)$.
Table 3: Comparison of transvaginal USG diagnosis with histopathological diagnosis of uterine fibroids $(n=35)$.

\begin{tabular}{|lccc|}
\hline $\begin{array}{l}\text { Sonographic } \\
\text { diagnosis }\end{array}$ & $\begin{array}{l}\text { Histopathological } \\
\text { diagnosis }\end{array}$ & Total \\
\hline & Fibroid & Non-fibroid & \\
\hline Fibroid & $34(\mathrm{TP})$ & $01(\mathrm{FP})$ & 35 \\
\hline Total & 34 & 01 & 35 \\
\hline
\end{tabular}

Table 4: Validity test for uterine fibroid.

\begin{tabular}{|l|c|}
\hline Validity test & Percentage \\
\hline Sensitivity & 94.4 \\
\hline Specificity & 85.71 \\
\hline Accuracy & 97.6 \\
\hline Positive predictive value & 97.1 \\
\hline Negative predictive value & 75 \\
\hline
\end{tabular}

Table 3 shows histopathological findings and TVS evaluation among 43 patients having a manifestation of fibroid. In TVS evaluation of uterine fibroids out of 43 cases true positive 34 and false positive 1, false negative 2 and true negative 6 cases.

Table 4 presents the results of the validity test of our study in terms of Sensitivity (94.4\%), specificity (85.71\%), positive predictive value $(97.1 \%)$, negative predictive value $(75 \%)$, and accuracy was $97.6 \%$.

\section{Discussion}

Transvaginal Sonography is a new imaging modality that is rapidly gaining acceptance among radiologist and obstetricians. This study was carried out with an aim to evaluate the role of transvaginal sonography in the diagnosis and evaluation of uterine fibroids in terms of localization, number and measurement. A total number of 43 consecutive patients (21-50 years) having suspected uterine fibroids who came in the department of Radiology \& Imaging of Mymensingh Medical College Hospital, Mymensingh, during the period of July 2012 to June 2014 were included in this study.

In this study, it was observed that the mean age of the patients was $37.6 \pm 7$ years and most of the patients having the fourth decade, which closely resembled with 
existing studies. For example, in Zhang et al. (2010) the mean age of the patients having uterine fibroids was $39.4 \pm 6.9$ year. Eight years range 30 to 49 years of the patients having uterine fibroids, on the other hand, Zaher et al.(2009) and Rajan et al.(2011) have higher mean age in their patients having uterine fibroids, which were 42.8 years and 43.8 years respectively they have stated that the higher age range may be due to increasing life expectancy in their study patients.

Fennessy and Tempany Fennessy and Tempany (2006) found in their study that Ultrasonography is usually goodat demonstrating well defined hypoechoic mass. Ultrasonography may demonstrate fociofincrease echogenicity if the calcification is present as it provides good inherent tissue contrast. In our study, the appearance of fibroids in TVS, we observed that hypoechoic mass in $65.7 \%$ patients, mixed echoic in $28.6 \%$ and calcification in $5.7 \%$ patients.

The number of uterine fibroids was evaluated by TVS. Most of the fibroids patients (54.2\%) had uterine fibroid, which is consistent with existing studies, including Zaher et al. (2009); Zhang et al.(2010). For example, authors in Zaher et al. (2009) found that patients with single fibroid were $61.0 \%$ and with multiple fibroids was $39.0 \%$. Similarly, Zhang et al. (2010) showed the single fibroid was more common in their studied patients.

In this study, we have identified the location of uterine fibroids by TVS. We found that most of the uterine fibroids were in the posterior wall of the body, which is $45.7 \%$. Other locations were the anterior wall of the body $(28.6 \%)$, both wall $(20 \%)$ and fundus (5.7\%). Locations of fibroids in our studied patients are little different from the existing study Zhang et al. (2010). In the study, $38.1 \%$ fibroids were located at the anterior wall of the uterus, $23.8 \%$ at the posterior wall of the uterus, $33.3 \%$ at the fundus, and $14.3 \%$ at the lateral wall.
We also measured the size of the uterine fibroids by TVS. The mean size was $3.7 \pm 1.6$ $\mathrm{cm}$ with a range from 1.9 to $7.5 \mathrm{~cm}$. Authors in an existing study Zhang et al. (2010) measured the fibroid size, and according to their study, the mean size of fibroids was $6.0 \pm 1.6 \mathrm{~m}$ range, $2.99 .5 \mathrm{~cm}$ in the greatest diameter. This study slightly differs with our study, and this may be due to geographical variation or early presentation.

We have identified the type of uterine fibroid of the patients using TVS.

According to our observation, $22.9 \%$ was Submucosal, almost two-third $71.4 \%$ was Intramural, and $5.7 \%$ was Subserosal type. Also, we found $18.7 \%$ of patients had no fibroid. Similar to our study, authors in Volkers et al. (2008) identified that out of fibroid patients, $25.0 \%$ was submucosal, $65 \%$ was intramural, and $10 \%$ was the subserosal type.

Finally, we have run a validity test for our study. The sensitivity was $94.4 \%$, specificity was $85.71 \%$, accuracy was $97.6 \%$, positive predictive values were $97.1 \%$, and the negative predictive value was $75 \%$. The validity test results were comparable to existing study Becker et al. (2002).

From the results of this study and the observations found in several existing studies, it can be concluded that transvaginal sonography is a useful, cheap and safe imaging modality to evaluate uterine fibroids.

\section{Conclusion}

Transvaginal ultrasonography is a safe and effective method of detecting uterine fibroids. It is suitable for pelvic organ imaging because of its high availability, portability, versatility, lack of reliance on organ function and lack of ionizing radiation. With TVS as an initial imaging modality, time and cost to arrive at diagnosis can be significantly reduced. However, it has a range of diagnostic problems, and associations with clinical, radiological and histological results are helpful in achieving the correct diagnosis. 


\section{Acknowledgments}

Special thanks to the peoples from the Department of Radiology and Imaging, Mymensingh Medical College and Hospital, Bangladesh, for their support.

\section{Declarations}

Conflict of interest: No conflict of interests.

Authors' Contribution: Muktadira (student) did the collection and result analysis. A. S. M. Mahbubur Rahman is the co-supervisor of the project. MutaTahHira helped in reviewing the paper, and M. A. Razzaque formatted the paper in latex (JBA format) and reviewed it.

Ethical approval: Ethical clearance for this study was taken from "Mymensingh Medical College Hospital, Mymensingh, Bangladesh" as appropriate.

\section{References:}

1. Aflatoonian AMM. Transvaginal ultrasonography in female infertility evaluation. Donald school journal of ultrasound inobs and gynecology. 2011;5(3),311-316.

2. Becker E, Lev-Toaff AS, Kaufman EP, Halpern EJ, Edelweiss MI, Kurtz AB. The added value of transvaginal sonohysterography over transvaginal sonography alone in women with known or suspected leiomyoma. J Ultrasound Med.2002;21(3),237-247.

3. Bhatiyani BR, Dhumale S, Pandeeswari $B D$. Correlation between ultrasonographic, hysteroscopic and histopathological findings in patients with abnormal uterine bleeding. Int J Reprod Contracept Obstet Gynecol, 2018;7(8),3250-6.

4. Chaparala RPC, Fawole AS, Ambrose NS, Chapman $A H$. Large bowel obstruction due to a benign uterine leiomyoma. Gut. 2004;53(3), 386- 386.

5. Fennessy FM, Tempany CM. A review of magnetic resonance imaging-guided focused ultrasound surgery of uterine fibroids. Topics in Magnetic Resonance Imaging. 2006; 17(3), 173-179.
6. Ferdows JA, Jahan I, Joty FS, Jahan $R$, Susan ZS, Ghani A. Role of Transvaginal Ultrasound in Infertility: Experience at a Tertiary Care Hospital in Dhaka City. Journal of Science Foundation. 2017;15(2),41-47.

7. Ferreira HP. Pathology in Gynecology and Obstetrics. J Clin Pathol. 1971;24(6),584584.

8. Garg K, Tickoo SK, Soslow RA, Reuter VE. Morphologic features of uterine leiomyomas associated with hereditary leiomyomatosis and renal cell carcinoma syndrome: a case report. Am. J. Surg. Pathol.2011;35(8), 1235-1237.

9. Ibrar F Riaz S DNJA. Frequency of fibroid uterus in multipara women in a tertiary care centre in Rawalpindi.J Ayub Med Coll Abbot-tabad.2010;22(3), 155-7.

10. Jr HF. Uterine fibroids. Diagnosis and indications for treatment. ObstetGynecol Clin North Am. 1995;22(4),659-65.

11. Murase E, Siegelman ES, Outwater EK, Perez-Jaffe $L A$, Tureck RW. Uterine Leiomyomas: Histopathologic Features, MR Imaging Findings, Differential Diagnosis, and Treatment. Radio Graphics. 1999;19(5),1179-1197.

12. Parker WH. Etiology, symptomatology and diagnosis of uterine myomas. Fertility and Sterility.2007;87(4), 725 - 736.

13. Podar L. Ultrasound evaluation of the uterus.Ultrasonography in obstetrics and gynecology. 2008: pp. 919-41.

14. Prayson RA HW. Pathologic considerations of uterine smooth muscle tumors. Obstet Gynecol Clin North Am.1995;22(4), 637-57.

15. Rajan DK, Margau R, Kroll RR, Simons $M E$, Tan KT, Jaskolka JD, Kachura JR, Sniderman KW, Beecroft JR, Haider $M$. Clinical utility of ultrasound versus magnetic resonance imaging for deciding to proceed with uterine artery embolization for presumed symptomatic fibroids. Clin Radiol. $2011 ; 66(1), 57-62$. 
Original Article

16. Rein MS, Barbieri RL, Friedman AJ. Progesterone: A critical role in the pathogenesis of uterine myomas. American Journal of Obstetrics \& Gynecology. 1995; 172(1), 14-18.

17. Sudderuddin $S$, Helbren E, Telesca $M$, Williamson R, Rockall A. MRI appearances of benign uterine disease. Clinical Radiology. 2014;69(11), 1095- 1104.

18. Volkers NA, Hehenkamp WJK, Spijkerboer $A M$, Moolhuijzen AD, Birnie E, Ankum WM, Reekers JA. MR Reproducibility in the Assessment of Uterine Fibroids for Patients Scheduled for Uterine Artery Embolization. Cardio Vascular and Interventional Radiology. 2008;31(2),260-268.

19. Walker CL, Stewart EA (2005). Uterine Fibroids: The Elephant in the Room. Science. 2005;308(5728), 1589-1592.

20. Wallach EE, Vlahos NF. Uterine myomas: an overview of development, clinical features, and management. Obstet Gynecol. 2004;104(2), 393- 406.

21. Wilde S, Scott-Barrett S. Radiological appearances of uterine fibroids. Indian Journal of Radiology and Imaging. 2009;19(3),222231.

22. Wo'zniak A, Wozniak S. Ultrasonography of uterine leiomyomas. Przeglad menopauzalny= Menopause review. 2017;16(4), 113.

23. Yeh HC K. Parasitic and pedunculated leiomyomas: ultrasonographic features. $J$ Ultrasound Med.1999;18(11),789-94.

24. Zaher S, Gedroyc WM, Regan L. Patient suitability for magnetic resonance guided focused ultrasound surgery of uterine fibroids. European Journal of Obstetrics \& Gynecology and Reproductive Biology. 2009;143(2),98102.

25. Zhang L, Chen WZ, Liu YJ, Hu X, Zhou K, Chen L, Peng S, Zhu H, Zou HL, Bai J, Wang $Z B$. Feasibility of magnetic resonance imaging-guided high intensity focused ultrasound therapy for ablating uterine fibroids in patients with bowellies anteriortouterus. European Journal of Radiology.2010;73(2), $396-403$. 